\title{
VCS: Visitor Counter System Berbasis Nodemcu dan IoT
}

\author{
${ }^{1 *}$ Padma Nyoman Crisnapati, ${ }^{2}$ Putu Devi Novayanti, ${ }^{3}$ I Putu Hendika Permana \\ ITB STIKOM Bali ${ }^{1}$, ITB STIKOM Bali ${ }^{2}$, Harmoni Permata ${ }^{3}$ \\ *Email: crisnapati@stikom-bali.ac.id
}

\begin{abstract}
ABSTRAK
Perangkat IoT (Internet of Things) dapat membantu manusia dalam mengumpulkan berbagai informasi, termasuk menyimpulkan pola perilaku dengan bias semantik yang besar. Jaringan IoT memiliki kemampuan untuk menggunakan informasi yang diperoleh untuk melakukan manajemen pada dirinya sendiri ataupun perangkat lainnya. Salah satu pemanfaatan IoT adalah untuk mendapatkan informasi jumlah orang di tempat tertentu. Jika informasi ini dikombinasikan dengan yang lain, dapat membantu sistem berbasis IoT menemukan karakteristik lingkungannya. Dalam pengabdian ini, diusulkan penerapan penghitung jumlah pengunjung berbasis IoT. Penghitung jumlah pengunjung (VCS- Visitor Counter System) adalah alat yang digunakan untuk mengukur jumlah orang yang melintasi pintu masuk. Jika kita memerlukan informasi mengenai berapa jumlah orang yang ada pada suatu ruangan, maka hal ini bisa menjadi sebuah solusi sederhana. Penerapan alat ini bisa dugunakan pada toko ritel, event besar, gedung kantor, dan bangunan cerdas. Keuntungan penggunaan alat ini sebagai pemilik perusahaan yaitu dapat mendeteksi jumlah orang masuk dan keluar pada perusahaan tersebut, sehingga pemilik usaha dapat melakukan analisis dan membuat keputusan yang tepat berdasarkan data perhitungan yang dihasilkan. Riset ini dilakukan secara kerja sama terhadap sebuah perusahaan teknologi CV. Harmoni Permata. Sebagai sebuah Institusi pendidikan, kerjasama terhadap industri merupakan sebuah kegiatan yang harus dilakukan untuk hilirisasi produk agar menjadi sebuah produk komersial.
\end{abstract}

Kata kunci : sistem penghitung pengunjung, nodemcu, iot

\section{ABSTRACT}

The IoT tool can assist humans in gathering various information, including inferring behavior patterns with large semantic biases. The IoT network has the ability to use information obtained to carry out management on itself or other devices. One of the uses of IoT is to get information about the number of people in a certain place. If this information is combined with others, it can help the IoT-based system find its environmental characteristics. In this study, it is proposed the application of IoT-based visitor counters. The visitor count counter (VCS-Visitor Counter System) is a tool used to measure the number of people who pass through the entrance. If we need information about how many people are in a room, then this can be a simple solution. The application of this tool can be used in retail stores, large events, office buildings, and smart buildings. The advantage of using this tool as a company owner is that it can detect the number of people entering and leaving the company, so that the business owner can make an analysis and make the right decision based on the calculated calculation data. This research was conducted in collaboration with a technology company CV. Harmoni Permata. As an educational institution, cooperation with industry is an activity that must be carried out to downstream a product to become a commercial product.

Key words: visitor counter system, nodemcu, iot 


\section{PENDAHULUAN}

Harmoni Permata adalah perusahaan yang bergelut di bidang IT (information technology) atau yang sering disebut dengan teknologi informasi. Perusahaan ini berdiri pada tanggal 12 desember 2009 dan dipimpin oleh putra Bali yaitu I Putu Hendika Permana. Harmoni Permata didukung oleh sumber daya yang berpengalaman dalam bidang informasi dan teknologi, dan dengan berbekal ilmu, keahlian, dan semangat yang tinggi hadir untuk membantu konsumen yang memiliki kesulitan dalam bidang informasi dan teknologi (Permata, 2011).

Saat ini Harmoni Permata tidak hanya menangani pesanan dalam bentuk software, namun juga berupa perangkat berbasis mikrokontroller dan IoT. Terdapat beberapa order alat pendukung usaha yang mereka terima, salah satunya adalah alat penghitung jumlah pengunjung. Alat ini memiliki fitur pendeteksi jumlah orang keluar dan masuk dari sebuah ruangan atau toko. Namun terdapat kendala yang dialami oleh Harmoni Permata yaitu dalam mencari SDM yang menguasai bidang mikrokontroler dan IoT. Berdasarkan hal tersebut harmoni permata membutuhkan bantuan dalam pembuatan dan penerapan perangkat.

Berdasarkan uraian di atas ditemukan sebuah peluang kerjasama yang dapat dibentuk antara industri (Harmoni Permata) dengan perguruan tinggi (ITB STIKOM Bali) melalui program pengabdian masyarakat. Hal ini didukung dengan adanya IAPS (Instrumen Akreditasi Program Studi) 4.0 terbaru yang mewajibkan produk/jasa karya Dosen Tetap Program Studi (DTPS) yang diadopsi oleh industri (Sapto, 2019).

Pada pengabdian masyarakat ini dilakukan pembuatan dan pemasangan alat di kantor Harmoni Permata. Selain itu, juga telah diadakan pelatihan instalasi dan penggunaan alat. Pengabdian ini dilakukan dengan tujuan memberikan bantuan pada pihak industri dalam merancang dan memproduksi alat skala industri.

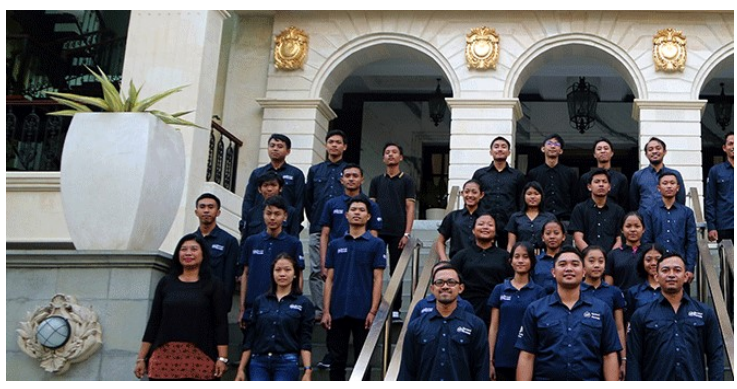

Gambar 1 Founder beserta Karyawan CV. Harmoni Permata

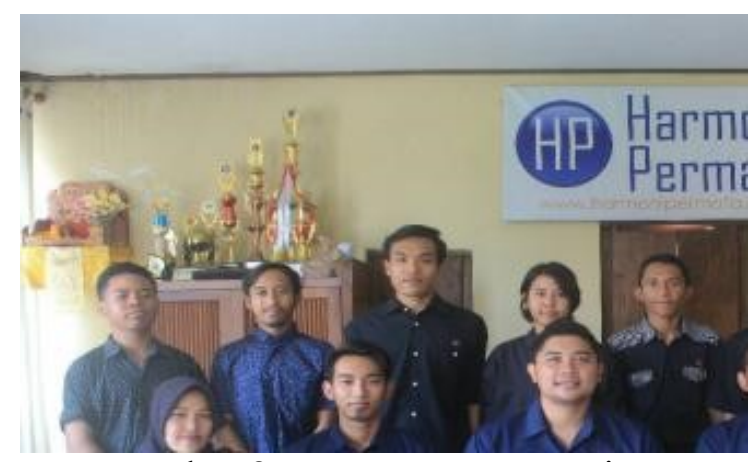

Gambar 2 Ruangan Kantor Mitra

\section{RUMUSAN MASALAH}

Hasil analisa situasi yang telah dilakukan menunjukkan bahwa terdapat beberapa masalah yang dihadapi oleh perusahaan I Putu Hendika Permana, adapun permasalahan prioritas dalam kegiatan pengabdian ini adalah kurangnya SDM (Sumber Daya Manusia) ahli yang menguasai bagaimana merancang dan membuat mikrokontroler dan IoT dengan skala industri. Sementara permintaan pasar terhadap kombinasi teknologi ini cukup banyak. Salah satunya adalah pesanan klien mengenai alat penghitung pengunjung yang dapat dimonitor secara realtime. Oleh karena itu, perlu diadakan kerjasama antar perguruan tinggi dalam merancang dan membuat alat tersebut.

\section{METODE}

Berdasarkan permasalahan yang menjadi prioritas maka terdapat enam tahapan (sosialisasi, pembuatan\& penerapan alat, pendaftaran HKI (Hak 
Kekayaan Intelektual), pelatihan, evaluasi, publikasi) untuk menangani permasalahan tersebut, seperti pada Gambar 3 berikut.

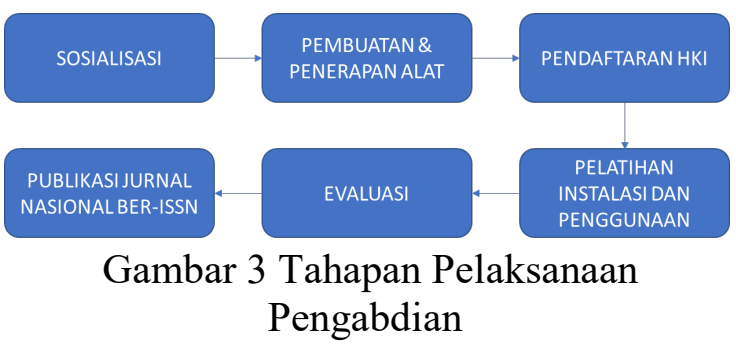

Tahap pertama adalah Sosialisasi dilaksanakan dengan menghadirkan mitra selaku peserta dalam pertemuan. Peserta adalah I Putu Hendika Permana beserta karyawan teknisi perusahaan. Pada pertemuan ini dilakukan pemaparan latar belakang dan tujuan dari pengabdian masyarakat.

Selanjutnya pembuatan alat akan dilakukan di Lab. Robotika ITB STIKOM Bali. Setelah alat selesai maka selanjutnya akan dilakukan penerapan/ pemasangan alat di PT. Harmoni Permata. Selama proses ini berlangsung telah diperoleh masukan untuk menyempurnakan alat hingga benar-benar siap digunakan oleh industri (Difusi Ipteks).

Setelah alat siap, selanjutnya dilakukan pendaftaran HKI oleh pihak pengembang dengan dipayungi oleh ITB STIKOM Bali. Selanjutnya dilaksanakan pelatihan instalasi dan penggunaan alat kepada karyawan PT. Harmoni Permata.

Evaluasi kegiatan dilakukan untuk mendapatkan masukan agar kedepannya pengabdian yang dilakukan lebih berbobot dan memiliki kualitas. Hasil dari keseluruhan pengabdian akan didokumentasikan dalam bentuk artikel yang dipublikasi pada Jurnal Nasional.

Lokasi pelaksanaan pengabdian masyarakat ini dilakukan dilakukan di kantor mitra PT. Harmoni Permata dengan pimpinan I Putu Hendika Permana yang beralamatkan di Jl. Merdeka IV No.17, Renon, Denpasar Selatan, Denpasar City, Bali 80239. Jarak antara lokasi pelaksana (kampus ITB STIKOM Bali) dan mitra adalah kurang lebih 3,1 Km. Pengabdian ini dilaksanakan dari bulan November 2019 sampai dengan Juni 2020.

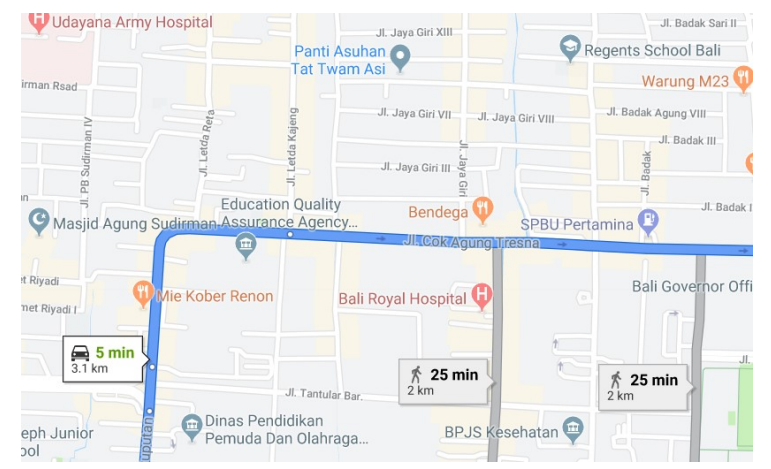

Gambar 4 Lokasi Mitra CV. Harmoni Permata

\section{PEMBAHASAN}

Sebagai tahap awal dari pengabdian ini dilakukan sebuah perancangan terhadap alat penghitung jumlah pengunjung. Proses yang dilakukan pertama kali adalah pembuatan flowchart sistem dan juga skematik rangkaian elektronika (Gambar 5 \& 6).

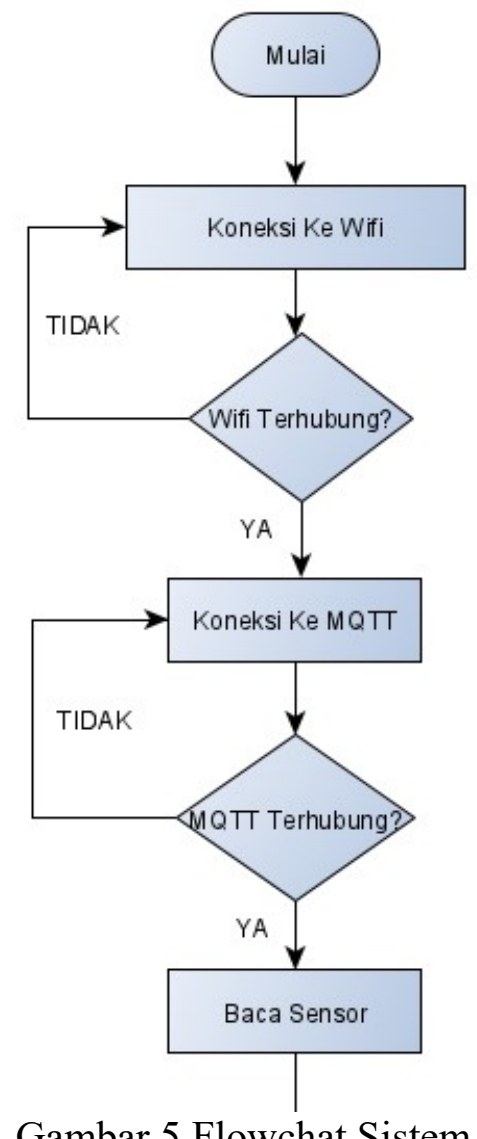

Gambar 5 Flowchat Sistem 


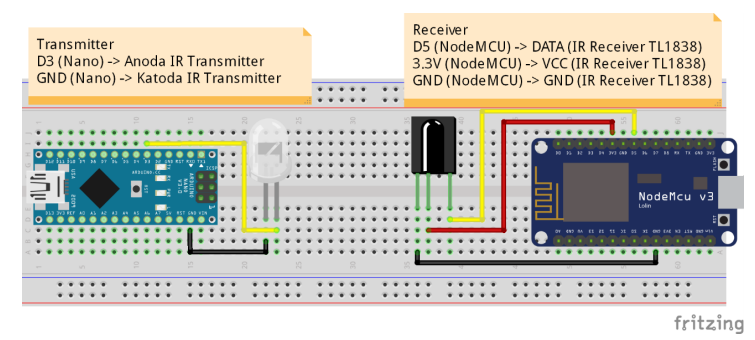

Gambar 6 Skematik Rangkaian Elektronika

Alat pendeteksi terdiri dari dua alat yaitu pengirim sinyal dan penerima sinyal (Gambar 7), cara kerja daripada alat ini yaitu pengirim sinyal mengirimkan data kepada penerima sinyal lalu apabila sinyal tidak diterima itu menandakan terdapatnya halangan (manusia) antara alat penerima dan pengirim. Data tersebut dikalkulasikan dan dikirim ke internet (server) melalui koneksi wifi (gambar 8) sehingga dapat ditampilkan dalam antarmuka web (Gambar 9). Sistem ini menampilkan data jumlah pengunjung yang masuk dan keluar. Untuk mengetahui data bersih pada setiap harinya maka total pengujung dibagi dua. Adapun perangkat yang digunakan agar memungkinkan data diperoleh secara realtime adalah nodemcu esp8266. Perangkat ini banyak digunakan oleh beberapa penelitian berkaitan dengan teknologi IoT (pengukuran jarak, smart home, hidroponik, data gempa, dan lain lain) (Barai, 2017)(Kashyap, 2018)(Crisnapati, 2016)(Crisnapati, 2017). Alasan dipilihnya nodemcu esp8266 dari segi biaya tergolong low cost sehingga harga alat lebih terjangkau. Selain itu esp8266 memiliki fitur yang lengkap dan praktis dalam hal penggunaan.

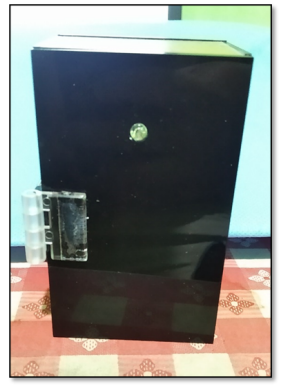

(a)

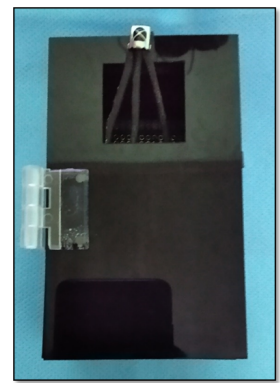

(b)
Gambar 7 (a) Pengirim Sinyal (b) Penerima Sinyal

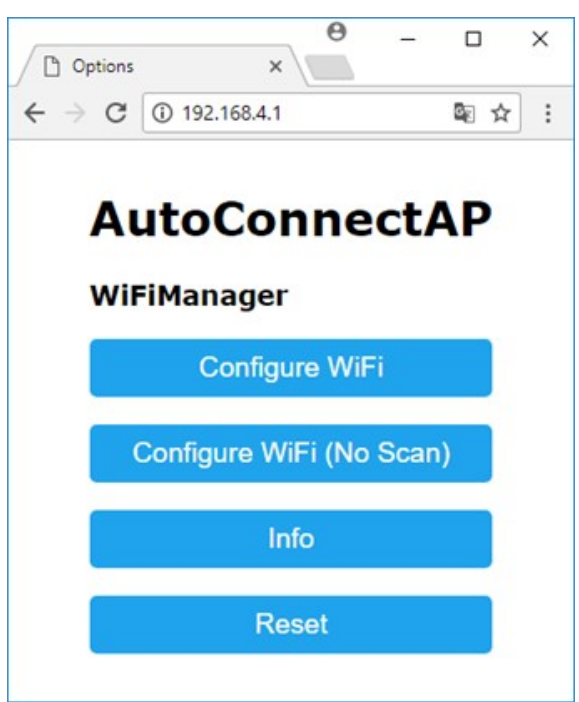

Gambar 8 Halaman Pengaturan Koneksi Alat

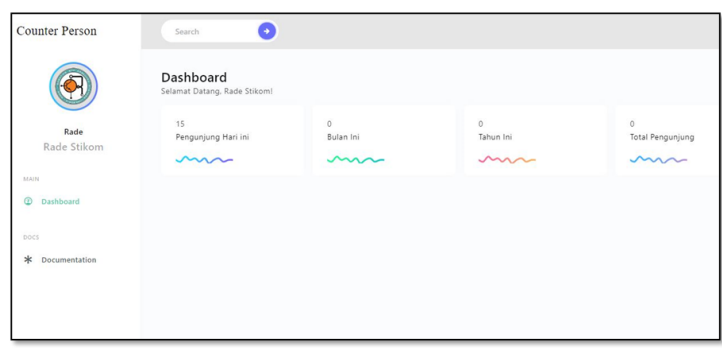

Gambar 9 Halaman Utama Sistem

Pada gambar 10 - 12 telah dilakukan demo dan penerapan alat penghitung jumlah orang yang keluar dan masuk ruangan. Gambar 10 dilakukan proses penjelasan mengenai alur daripada sistem. Sedangkan pada gambar 11 dijelaskan skematik rangkaian elektronika daripada alat. Pada gambar 12 dilakukan proses demo alat pada salah satu karyawan CV. Harmoni Permata.

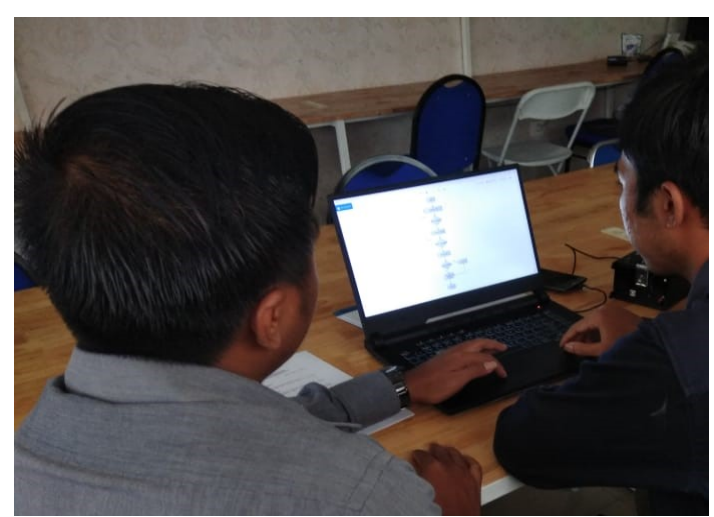

Gambar 10 Demo Flowchat Sistem 


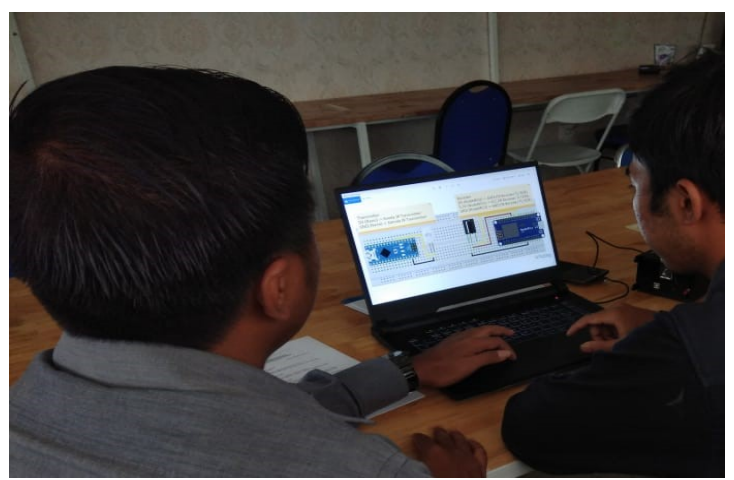

Gambar 11 Penjelasan Rancangan Skematik Alat

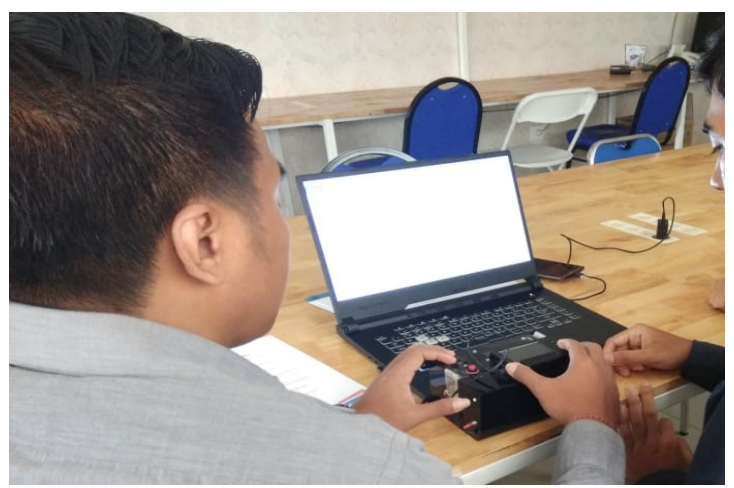

Gambar 12 Demo Alat Visitor Counter System

\section{SIMPULAN}

Kegiatan pengabdian kepada masyarakat telah menghasilkan VCSVisitor Counter System Berbasis Nodemcu dan IoT pada CV. Harmoni Permata. Sistem telah berhasil dirancang dan diimplementasikan dengan baik, berdasarkan hasil demo/pelatihan pemasangan alat pada CV. Harmoni Permata. Sistem ini diimplementasikan dengan fitur yang sederhana namun sudah memenuhi kebutuhan konsumen. Hal ini berkaitan erat dengan pengurangan biaya alat agar dapat diproduksi oleh CV. Harmoni Permata dan bersaing dengan produk serupa yang sudah beredar di pasar.

\section{UCAPAN TERIMA KASIH}

Ucapan terima kasih dipersembahkan kepada I Putu Hendika Permana selaku founder CV. Harmoni Permata sekaligus mitra, dan ITB STIKOM Bali selaku penyedia sumber dana daripada pengabdian masyarakat ini.

\section{DAFTAR PUSTAKA}

Barai, S., Biswas, D. and Sau, B., 2017, December. Estimate distance measurement using NodeMCU ESP8266 based on RSSI technique. In 2017 IEEE Conference on Antenna Measurements \& Applications (CAMA) (pp. 170-173). IEEE.

Crisnapati, P.N., Wardana, I.N.K., Aryanto, I.K.A.A. and Hermawan, A., 2017, August. Hommons: Hydroponic management and monitoring system for an IOT based NFT farm using web technology. In 2017 5th International Conference on Cyber and IT Service Management (CITSM) (pp. 1-6). IEEE.

Crisnapati, P.N., Wardana, I.N.K. and Aryanto, I.K.A.A., 2016, May. Rudas: Energy and sensor devices management system in home automation. In 2016 IEEE Region 10 Symposium (TENSYMP) (pp. 184-187). IEEE.

Crisnapati, P.N., Wardana, I.N.K. and Aryanto, I.K.A.A., 2016, May. Rudas: Energy and sensor devices management system in home automation. In 2016 IEEE Region 10 Symposium (TENSYMP) (pp. 184-187). IEEE.

Kashyap, M., Sharma, V. and Gupta, N., 2018. Taking MQTT and NodeMcu to IOT: Communication in Internet of Things. Procedia computer science, 132, pp.1611-1618.

Permata, H. 2011. Tentang-Kami. https://harmonipermata.com/tentangkami/. 01 Juni 2020 (15:00).

Sapto. 2019. APS9. BAN-PT. https://sapto.banpt.or.id/borang/aps9.zip.
01
Juni
2019
$(15: 00)$ 